\title{
EVENTO EXTREMO DE CHUVA-VAZÃO NA BACIA HIDROGRÁFICA DO RIO ARAGUARI, AMAPÁ, BRASIL
}

ALAN CAVALCANTI DA CUNHA ${ }^{1}$ JEFFERSON ERASMO DE SOUZA VILHENA, ${ }^{2}$ ELDO SILVA DOS SANTOS ${ }^{1}$ JACI MARIA BILHALVA SARAIVA $^{3}$ PAULO AFONSO FISCHER KUHN ${ }^{4}$ DAÍMIO

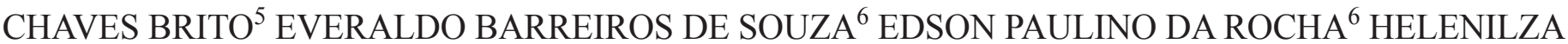
FERREIRA ALBUQUERQUE CUNHA ${ }^{1}$ ALAAN UBAIARA BRITO ${ }^{1}$ ANTÔNIO CÉSAR PINHO BRASIL JÚNIOR $^{7}$ VICTOR HUGO DA MOTTA PACA ${ }^{8}$ PAULA VERÔNICA CAMPOS JORGE SANTOS ${ }^{1}$

\author{
${ }^{1}$ Universidade Federal do Amapá (UNIFAP), Macapá, AP, Brasil \\ ${ }^{2}$ Núcleo de Hidrometeorologia e Energia Renováveis/Instituto de Pesquisas Científicas e Tecnológicas do \\ Estado do Amapá (NHMET/IEPA), Macapá, AP, Brasil \\ ${ }^{3}$ Sistema de Proteção da Amazônia (SIPAM), Manaus, AM, Brasil \\ ${ }^{4}$ Universidade Federal do Amazonas (UFAM), Manaus, AM, Brasil \\ ${ }^{5}$ Universidade Estadual do Amapá (UEAP), Macapá, AP, Brasil \\ ${ }^{6}$ Universidade Federal do Pará (UFPA), Faculdade de Meteorologia, Belém, PA, Brasil \\ ${ }^{7}$ Universidade de Brasília (UnB), Brasília, DF, Brasil \\ ${ }^{8}$ Serviço Geológico do Brasil (CPRM-PA), Belém, PA, Brasil
}

alancunha12@gmail.com,jeffersonerasmo@hotmail.com, eldo@unifap.br, jaci.saraiva@sipam.gov.br

Received September 2013 - Accepted April 2014

\section{RESUMO}

O objetivo da investigação foi analisar vazões extremas ocorridas entre 9 e 14 de abril de 2011 na bacia do Rio Araguari-AP. A metodologia consistiu de três etapas principais: 1) re-análise da precipitação estimada pelo Modelo BRAMS (Brazilian in Development Regional Atmospheric Model System),utilizando como suporte a sinótica do mesmo período; 2) análise de vazão nas seções de monitoramento hidrológico em Porto Platon, Capivara e Serra do Navio (ADCP-Accustic Doppler Profiller Current); 3) análise estatística da série histórica de vazões máximas em Porto Platon utilizando distribuição de Gumbel. Observou-se que o modelo BRAMS capturou parcialmente o padrão do sistema de precipitação quando comparado com a análise sinótica e com os dados da literatura, mas demandando ainda otimização na representação de respostas hidrológicas extremas. Em Porto Platon foi registrada uma vazão recorde de $4036 \mathrm{~m} 3 / \mathrm{s}$, cujo comportamento foi analisado sob a ótica dos mecanismos disponíveis de monitoramento no Estado. Concluiu-se que tais eventos extremos são pouco detectáveis e oferecem riscos consideráveis aos usuários da bacia. A previsão de vazão, baseada na série hidrológica disponível, era de 100 anos de retorno, mas as análises revelaram que este período seria de 360 anos, indicando significativa fragilidade do sistema de previsão de eventos extremos no Estado.

Palavras-chave: Processo Hidrológico; Evento Extremo; Previsão; Observação; Chuva-vazão.

ABSTRACT: EXTREME PRECIPITATION-STREAMFLOW EVENT IN THE RIVER ARAGUARI BASIN, AMAPÁ/BRAZIL

The objective of this investigation was to analyse the extreme river flows which have occurred between 9 and 14 April 2011 in the Rio Araguari-AP. The methodology consisted of three main steps: 1) reanalysis of precipitation estimated by the BRAMS (Brazilian Development in Regional Atmospheric Model System) model using the synoptic of the same period as support, 2) analysis of streamflow in sections of hydrological monitoring in Porto Platon, Capivari and Serra do Navio (ADCP-Accustic 
Profiller Doppler Current); 3) statistic analysis of the time series of maximum river flows in Porto Platon using Gumbel distribution. It was observed that the BRAMS system partially captured the standard precipitation when compared with the synoptic analysis and literature data, but the extreme hydrological responses representation still needs an optimization. In Porto Platon a flow record of 4036 $\mathrm{m} 3 / \mathrm{s}$ was recorded, whose behavior was analyzed from the perspective of the available monitoring mechanisms in the State. It was concluded that such extreme events are poorly detectable and offer considerable risks to users of the basin. The stream flow prediction based on available hydrological series was 100 years recurrence, but the analysis have revealed that this period would be 360 years, indicating significant deficiency of the prediction system of extreme events in the State.

Keywords: Rainfall-runoff; Hydrological Process; Extreme Event; Forecast; Liquid discharger.

\section{INTRODUÇÃO}

Mudanças profundas no clima no Brasil têm sido anunciadas, conforme a região do país, como as que podem afetar ecossistemas aquáticos e terrestres de toda a bacia da região amazônica. Dentre as mudanças mais relevantes, os processos hidrológicos e ecológicos em bacias, zonas costeiras estuarinas e oceânicas são frequentemente citados (Ward et al., 2013; Skutel et al., 2013; Cunha, 2013).

Segundo PBMC (2012) já estão disponíveis estudos sobre os possíveis efeitos de alterações climáticas nos recursos hídricos do Brasil. Dentre as bacias hidrográficas mais importantes do país, segundo seus atributos hidrológicos e ecológicos, encontra-se a do Amazonas, que drena regiões que podem sofrer diferentes impactos relacionados às alterações de temperatura e precipitação (volume e frequência de chuvas), com efeitos distintos na disponibilidade de água para uso humano (Tucci, 1998; Oliveira et al., 2010) e manutenção de processos ecológicos (Neves et al., 2011; Cunha et al., 2013; Ward et al., 2013).

Regionalmente os cenários climáticos convergem para a redução dos índices pluviométricos nos meses de inverno em todo o país, assim como no verão no leste da Amazônia e Nordeste (Souza et al., 2009; Neves et al., 2011). Contudo, ainda é necessário melhorar o tratamento e a avaliação de incertezas sobre tendências projetadas em bacias hidrográficas (Naghettini e Pinto, 2007), sendo necessário avaliá-los com o desenvolvimento de modelos usados para gerar projeções climáticas (Souza et al., 2009; Neves et al., 2011).

Souza et al. (2009) descrevem que a região Amazônica apresenta regime pluviométrico elevado, além de uma significativa variabilidade espacial e temporal, que podem ser verificadas pela distribuição de precipitação sobre diversas sub-regiões e em diferentes épocas do ano. Esta variabilidade climática, em diversas escalas, tem sido motivo de preocupação de estudiosos na tentativa de explicar coerentemente questões complexas. Uma destas questões fundamentais seria: como os processos hidrológicos das bacias hidrográficas são impactados pela rápida mudança da dinâmica atmosférica (Figueroa e
Nobre, 1990; Lopes, 2009; Soito Junior e Freitas, 2011). Tais questionamentos sobre o comportamento da precipitação na região amazônica é tema recorrente devido às incertezas sobre este parâmetro hidromteorológico no curto, médio e longo prazos (Souza e Rocha, 2006; Souza et al., 2009; Lopes, 2009).

No Estado do Amapá, há diversas lacunas de conhecimento sobre este tema e que necessitam ser superadas, com destaque aos processos hidrológicos em bacias hidrográficas (Souza e Cunha, 2010). Portanto estes argumentos se justificam devido ao crescente interesse por informações hidrometeorológicas necessárias aos usuários de bacias hidrográficas, tais como, a otimização da tomada de decisão e melhoria da eficiência de gestão de recursos hídricos, cujo objetivo seria minimizar riscos decorrentes de eventos extremos ou a eles associados (Cunha et al., 2011; Cunha et al., 2013; Santos, 2012).

Mas este desafio é ainda tarefa difícil de empreender. A exemplo dos eventos extremos de precipitação ocorridos na bacia do rio Araguari-AP (secas e cheias extremas observadas desde 2004), as oscilações de precipitação têm sido relacionadas com a variabilidade do clima da Amazônia Oriental (Souza e Cunha, 2010; Souza et al., 2009; Neves et al., 2011).

Considerando que a maioria dos eventos extremos no Brasil está relacionada com eventos de El Niño e La Niña, as mudanças de comportamento do ENOS são extremamente importantes (Souza et al., 2009; Neves et al., 2011) porque, se o aumento da frequência de El Niños "Modoki" devido ao aquecimento global continuar, de acordo com PBMC (2012), haverá o desenvolvimento mais frequente de: (i) fases negativas do modo dipolo do Atlântico Sul (polo equatorial quente e polo subtropical frio); (ii) anomalias quentes de TSM no Atlântico Equatorial; e (iii) anomalias menos quentes ou neutras de TSM no Atlântico Norte Tropical, caracterizando uma fase negativa do modo meridional (gradiente meridional de TSM negativo).

Alguns estudos observacionais têm indicado tendência positiva na amplitude de eventos ENOS, sugerindo como causa o aquecimento global (Freitas et al., 2009). Estas análises têm sido complementadas por intermédio de experimentos numéricos envolvendo Modelos Acoplados de Circulação Geral, com a imposição de aumento na concentração dos gases 
de efeito estufa. Apesar destes esforços complementares, ainda há incertezas consideráveis se essa tendência de aumento da amplitude do ENOS resulta do aquecimento global ou da variação natural do sistema climático global.

Com relação a La Niña ainda não se tem previsão do que ocorrerá, podendo potencialmente apresentar um efeito oposto. Os últimos eventos de La Niña de 2008/09 acarretaram secas na Amazônia, ao passo que as chuvas intensas e enchentes verificadas em 2011/12 também ocorreram durante um evento de La Niña. Neste caso, este efeito também parece ter tido forte influência nas precipitações na bacia do rio Araguari-AP em abril de 2011 (Santos, 2012; Cunha, 2013).

Por outro lado, a seca de 2005/06 na Amazônia foi considerada um evento com período de retorno da ordem 100 anos. Contudo, em 2010, ocorreu também seca de magnitude comparável, mas que afetou outra área da Amazônia. Todos estes eventos extremos têm reforçado a hipótese de aumento de suas frequências, além de serem provavelmente mais intensos em face das mudanças climáticas em curso. Segundo Souza et al. (2009) e Souza e Cunha (2010), a variação decadal (em escalas de 25-30 anos) no Oceano Pacífico ou Atlântico apresentam menor diferença entre fases opostas, mas são relevantes em termos de adaptação porque são persistentes, podendo causar secas prolongadas ou décadas com mais eventos extremos de chuva em várias regiões da América do Sul (dipolos positivo e negativo) que podem afetar fortemente setores importantes da economia, como o hidrelétrico.

Soito Junior e Freitas (2011) afirmam que a Amazônia e o Nordeste brasileiros são considerados hot spots que representam as regiões hidrologicamente mais vulneráveis do Brasil em face às mudanças climáticas, haja vista que os modelos projetam aumento de temperatura, mas não concordam em relação às mudanças dos padrões de chuva. Estas contradições sugerem que as análises de precipitação em nível de mesoescala não representam muito bem seus reais efeitos em muitas bacias da Amazônia.

Em um país com dimensões continentais e extensa malha hidrográfica como o Brasil, nem todas as bacias são devidamente monitoradas e, nesse caso, adensar a rede hidrométrica não é tarefa das mais simples. Segundo Pessoa et al. (2011) uma rede hidrométrica raramente possui densidade de estações que pode cobrir todos os locais de interesse de um plano de gerenciamento de recursos hídricos. Por esta razão é fundamental para a Amazônia entender a evolução temporal de eventos hidrológicos em suas bacias para, por exemplo, construir microcentrais ou novas hidrelétricas e operar as já existentes (Cunha et al., 2011; Blanco et al., 2007). Primeiro, porque permite estudar a sensibilidade das variações hidrológicas das bacias hidrográficas com diferentes geometrias e características para realizar um dimensionamento inicial dos fenômenos físicos envolvidos.
Segundo, possibilitar o planejamento e a análise de consistência de séries históricas e preenchimento de falhas (Tucci, 1998; Naghettin e Pinto 2007 e Souza et al., 2010).

Mas, de acordo com Oliveira et al. (2010), geralmente os dados de chuva disponíveis não são muito numerosos, mesmo sendo relativamente mais abundantes que as demais informações hidrométricas solicitadas para projetos hidráulicos. Este fato induz a erros nas avaliações realizadas por métodos estatísticos, visto que têm de partir de pequenas amostras.

Mendiondo e Tucci (1997) descrevem que o ciclo hidrológico atua de forma integrada com outros ciclos de energia e matéria, num intervalo amplo de escalas espaciais e temporais, sendo que alguns dos principais desafios da hidrologia são: a representatividade dos processos hidrológicos em diferentes escalas espaciais e temporais; o empirismo de modelos e parâmetros representativos dos processos hidrológicos na bacia hidrográfica; e a integração de modelos meteorológicos e hidrológicos. Contudo, a representação dos processos hidrológicos em diferentes escalas tem esbarrado nos seguintes aspectos principais: a heterogeneidade espacial dos sistemas hídricos e a incerteza com a qual os parâmetros e processos são medidos em diferentes escalas; a dificuldade de representar os processos caracterizados e analisados na microescala para outras escalas da bacia hidrográfica; a falta de relação entre os parâmetros de modelos matemáticos com as diferentes configurações espaciais encontradas na natureza.

Reforçando este argumento Alexandre et al. (2013) estudaram dados de chuva-vazão de 18 bacias no semi-árido do Nordeste para fins de análise de construção de reservatórios artificiais superficiais, e quantificaram o efeito de escala nas bacias mais afetadas pela pequena açudagem com área de drenagem inferiores a $5.000 \mathrm{~km} 2$. Para bacias de maior porte, o impacto desta pequena açudagem não foi detectada a partir de uso de modelo hidrológico. Os referidos autores concluíram que a geração de séries de vazões, utilizando modelagem hidrológica, em locais com alto grau de saturação de reservatórios superficiais artificiais, exige-se uma análise diferenciada com o uso de modelos de transformação chuvavazão, que levem em consideração o efeito causado por estes reservatórios na geração dos deflúvios da bacia em estudo.

Por outro lado, Silans et al. (2009) analisaram o efeito da representatividade espacial da precipitação diária sobre a geração da curva de permanência em diversos pontos de uma bacia hidrográfica do litoral nordestino utilizando o modelo hidrológico distribuído. Os referidos autores mostraram que a informação gerada pelo modelo se degrada para densidades inferiores a um posto pluviométrico para cada $65 \mathrm{~km}^{2}$, situação esta que se observa na maioria das bacias do litoral do Nordeste brasileiro, sugerindo que a sensibilidade do modelo e das curvas de permanência variam no espaço, dependendo de como se 
distribuem geograficamente os postos pluviométricos. Deste modo, mostraram que ocorre uma sensibilidade diferente quando se observa o hidrograma mensal, ou a curva de permanência.

Nesta perspectiva, de acordo com Blanco et al. (2007), o potencial hidrelétrico na Amazônia pode ser estimado somente nas grandes bacias, pois são as únicas que possuem dados de vazão. Este é o caso da bacia do rio Araguari, com 42 mil km2. Por exemplo, este critério desconsidera inúmeras pequenas bacias ou sub-bacias, que poderiam atender às pequenas comunidades isoladas mediante implantação de microcentrais hidrelétricas. Desta forma, como os dados pluviométricos são comumente disponíveis na região, estes podem ser utilizados, mediante análise, na aplicação e transposição de um modelo hidrológico tipo chuva-vazão para pequenas bacias hidrográficas da Amazônia.

$\mathrm{Na}$ presente investigação a vazão é a variável que caracteriza genuinamente o processo hidrológico de interesse na bacia, a qual apresenta um comportamento aleatório que exige adequada avaliação das suas séries históricas, de modo representativo e confiável (Tucci, 1998; Naghettini e Pinto, 2007; Shatfield, 2004). A previsão de vazões geralmente é realizada para eventos chuvosos, onde as dificuldades de antecedência são maiores, porque nos períodos de estiagem toda a água disponível já se encontra dentro da bacia e a previsão depende de metodologia determinista, que envolve o escoamento subterrâneo na bacia e a propagação do escoamento existente nos rios (Souza et al., 2010). Por outro lado, a previsão de cheia em tempo atual pode ser classificada de acordo com a antecedência desejada e com as características locais da bacia de drenagem.

O objetivo da presente investigação é realizar um estudo de caso representado pela re-análise do fenômeno de cheia extrema ocorrida no rio Araguari, Estado do Amapá/Brasil, entre os dias 09 a 14 de abril de 2011. Foram utilizadas saídas numéricas do modelo BRAMS (Brazilian in Development Regional Atmospheric Model System), as quais foram comparadas com dados de observações sinóticas durante o referido evento. Posteriormente às análises comparativas com o modelo BRAMS, foi elaborada uma avaliação da distribuição estatística de vazões máximas, que representaram a resposta da bacia à precipitação (chuva-vazão).

\section{MATERIAL E MÉTODOS}

\subsection{Descrição da área de estudo: bacia hidrográfica do Rio Araguari-AP}

Segundo Cunha et al. (2011) o rio Araguari apresenta uma extensa rede hídrica configurando-se no principal e maior rio genuinamente amapaense, com aproximadamente $617 \mathrm{~km}$ de comprimento e índice de drenagem da ordem de 0,955/ km (Figura 1). O rio Araguari nasce na região noroeste da

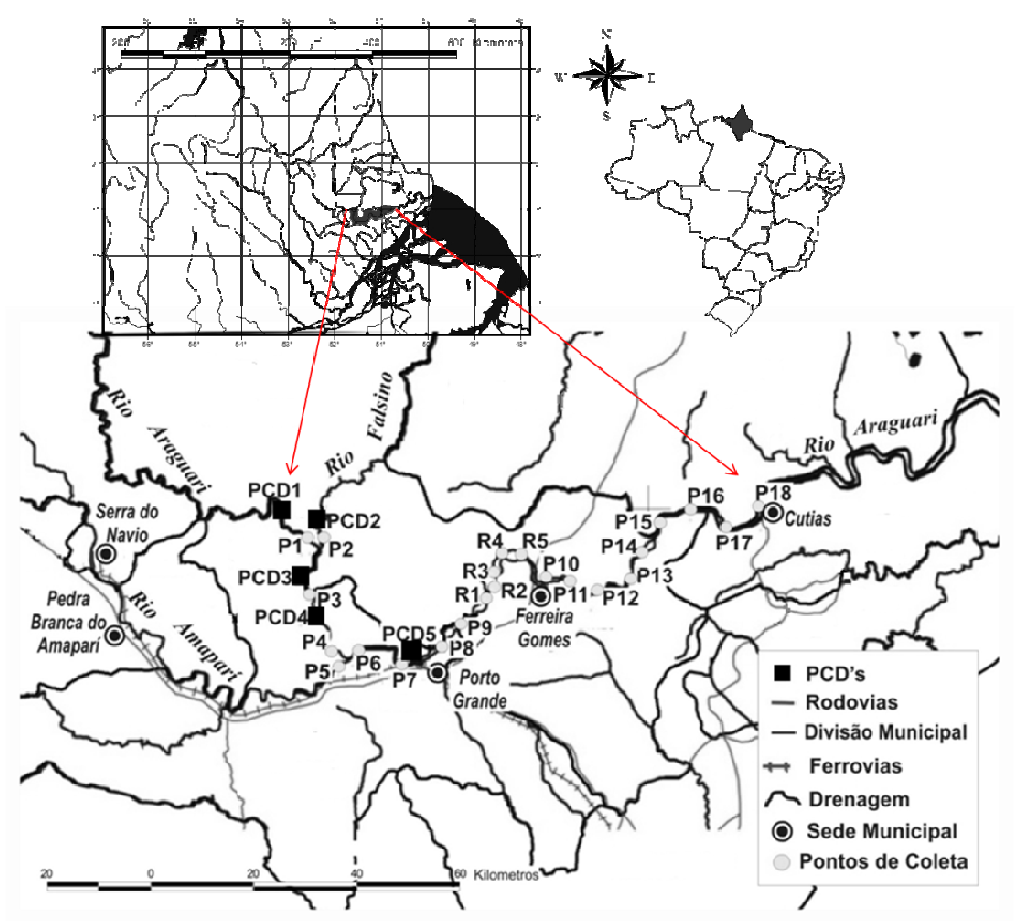

Figura 1: Mapa da bacia hidrográfica do Rio Araguari e localização do ponto de monitoramento P8 (Porto Platon) e algumas cidades e estações hidrológicas automáticas (indicadas como PCDs).

Fonte: Cunha et al. (2011). 
bacia hidrográfica, ao longo das regiões de topografias mais elevadas, com média $450 \mathrm{~m}$ acima do nível do mar, na Unidade de Conservação (UC) denominada Parque Nacional (PARNA) Montanhas do Tumucumaque, o segundo maior parque ambiental do mundo e o maior do Brasil. Além do PARNA, o rio Araguari banha outras UCs, tais como, a Floresta Nacional do Amapá (FLONA-AP), a Floresta Estadual do Amapá (FLOTA) e a Reserva Biológica do Lago Piratuba (REBIO) (Eletronorte, 1999; Cunha et al., 2011; Santos, 2012; Dias, 2013).

O canal principal do rio Araguari pode ser dividido em três trechos principais: a) Trecho Superior, compreendido entre a localidade de Porto Grande e a confluência do rio Tajauí, situada no final do trecho de montante (PCD1 da Figura 1), é um trecho senil, que apresenta desnível de 40,5 m em $191 \mathrm{~km}$, e gradiente de 0,212 m/km; b) Trecho Médio, compreendido entre as localidades de P1 até Ferreira Gomes, perpassando por Porto Grande, é um trecho juvenil, com muitas corredeiras. O desnível total desse trecho é de 54,40 m em 42 $\mathrm{km}$, que resulta em gradiente médio de $1,297 \mathrm{~m} / \mathrm{km}$; c) Trecho Inferior, compreendido entre $\mathrm{P} 11$ e a foz do rio, perpassando pela localidade de Ferreira Gomes e Cutias do Araguari, o qual está sujeito à influência das marés pelo Oceano Atlântico. Esse trecho tem um desnível muito baixo, de 1,0 m em $224 \mathrm{~km}$, com gradiente de somente $0,004 \mathrm{~m} / \mathrm{km}$ (Eletronorte, 1999).

De acordo com a Figura 1, o rio Araguari apresenta dois afluentes principais: o rio Amapari, o maior em volume de água, que aflui no seu curso contribuindo com aproximadamente 1/3 da vazão do rio Araguari; e o rio Falsino, o segundo maior, contribuindo com aproximadamente 1/4 da vazão do rio Araguari, antes da confluência deste com o rio Amapari. No trecho de jusante, os rios afluentes são relativamente pequenos quando comparados com o rio Araguari (contribuição afluente é distribuída ou difusa), não ultrapassando $10 \%$ da vazão total de jusante, com destaque aos rios Tracajatuba e Tabaco (Santos, 2012).
A Figura 2 mostra o comportamento hidrológico das vazões máximas de longo termo no rio Araguari (estação fluviométrica de Porto Platon - P8), próximo da cidade de Porto Grande. O fluxo de máximas vazões sofre ampla variação sazonal (e interanual) ao longo dos anos, variando entre 190 $\mathrm{m}^{3} / \mathrm{s}$ (novembro) e $4036 \mathrm{~m}^{3} / \mathrm{s}$ (abril) (ANA, 2012; Santos, 2012; Cunha, 2013). Observe que os círculos representam outliers (secas ou cheias extremas na série). Observam-se mais eventos extremos acima da mediana (fev, jul, set, out, dez) do que os abaixo da mediana (mar e mai).

\subsection{Dados de precipitação e vazão na bacia}

De acordo com Oliveira et al. (2010), os totais de precipitação estão disponíveis a partir de um conjunto de re-análises em grade de 0,5 versus $0,5 \mathrm{~km}^{2}$, fornecido pelo grupo de estudos climáticos da Universidade de DelawareEUA. Na Figura 3 encontram-se os registros de referência das médias anuais das variáveis de precipitação. Nesta região o total anual de chuva em média registrado foi da ordem de $2.389 \mathrm{~mm}$, com máximo observado de $2.962 \mathrm{~mm}$ e mínimo de $1.831 \mathrm{~mm}$. Souza et al. (2010) disponibilizam informações detalhadas sobre o comportamento das respostas de vazão para diferentes precipitações na bacia do rio Araguari. Na presente investigação, os dados de Oliveira et al. (2010) foram utilizados como referência para a análise sinótica do período de cheia extrema. A ausência de uma maior cobertura espacial de estações meteorológicas distribuídas em toda região norte do Brasil dificulta a análise de eventos extremos. Deste modo estes registros servem como referência do "padrão" espacial da precipitação na bacia. Este padrão foi comparado com as saídas do BRAMS/REMETAP em simultaneidade com a análise sinótica do evento extremo (Figura 3).

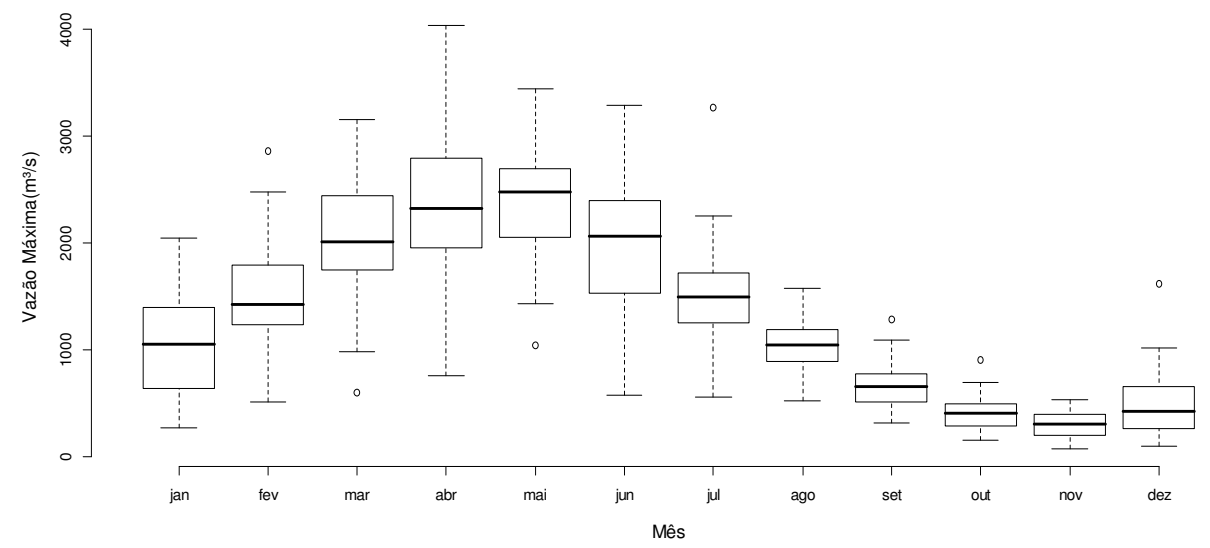

Figura 2: Variação das vazões máximas no Rio Araguari (m3/s) em Porto Platon $\left(0^{\circ} 42^{\prime 2} 27^{\prime} \mathrm{N}, 51^{\circ} 26^{\prime 2} 20^{\prime} \mathrm{O}\right)$, a montante do reservatório da UHE Coaracy Nunes. Série operacional: janeiro/1952 a agosto/1958 e junho/1972 a dezembro/2012. Registro recorde: Qmax =4.036 m³/s, em 14/04/2011 (Santos, 2012; ANA, 2013; Cunha, 2013). 


\subsection{Medidas de descarga líquida durante a ocorrência do evento extremo de chuva-vazão}

Os dados de vazões médias máximas na Estação de Porto Platon foram utilizados a partir das vazões diárias do sistema Hidroweb (ANA, 2012). Estas foram expandidas para mais três estações de monitoramento a montante da UHECN: estações de Porto Platon (Araguari), Capivara (Amapari) e Serra do Navio (Amapari), (PCD1, PCD4 e PCD7 na Figura 1).

As medidas de descargas líquidas extremas foram executadas em simultaneidade ao evento extremo utilizando-se um ADCP (Acoustic Doppler Current Profiller) RD Instruments, modelo WorkHorse Rio Grande, de 600kHz. Quatro campanhas foram concentradas num curto período entre 9 e 14 de abril de 2011. Para detalhes sobre o funcionamento do ADCP e o método de determinação da vazão com o ADCP WorkHorse Rio Grande, 600 kHz, RD Instruments, consultar Mueller e Wagner (2009), Muste et al. (2004) e Dinehart e Burau (2005).
Durante as medidas extremas de vazão, o ADCP foi instalado na lateral de um barco de madeira, dotado de um suporte não ferroso para não produzir interferência de campos eletromagnéticos no equipamento. $\mathrm{O}$ transdutor operou em nível de 0,60 m submerso. A Figura 4 mostra um esquema com a instalação do ADCP. Além das conexões, um GPS modelo GARMIN® 76CSx foi conectado ao computador para se obter as coordenadas geográficas das medidas e coletar os dados hidrométricos.

As medidas consistem em uma travessia onde o ADCP mede a região central da seção. Essa é a vazão efetivamente medida. A esta somam-se as vazões de fundo, topo e das margens direita e esquerda da seção de monitoramento, as quais são estimadas internamente por cálculo do equipamento através de extrapolações, adotando-se o método exponencial padrão para extrapolação da vazão (Mueller e Wagner, 2009). Durante a aquisição dos dados, por diversos motivos, o ADCP pode apresentar falhas de leitura de algumas células (bad bins)

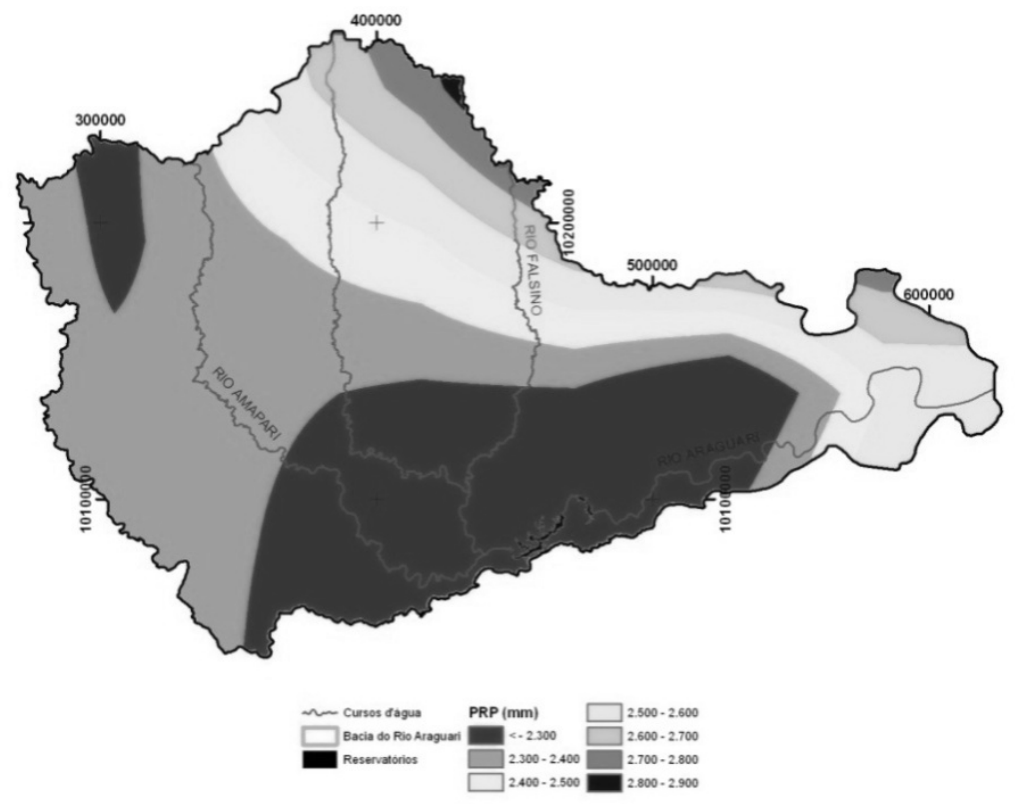

Figura 3: Distribuição da precipitação pluviométrica total anual da Bacia do Rio Araguari. Fonte de dados: University of Delaware (1979-2006). Fonte: Oliveira et al.(2010).
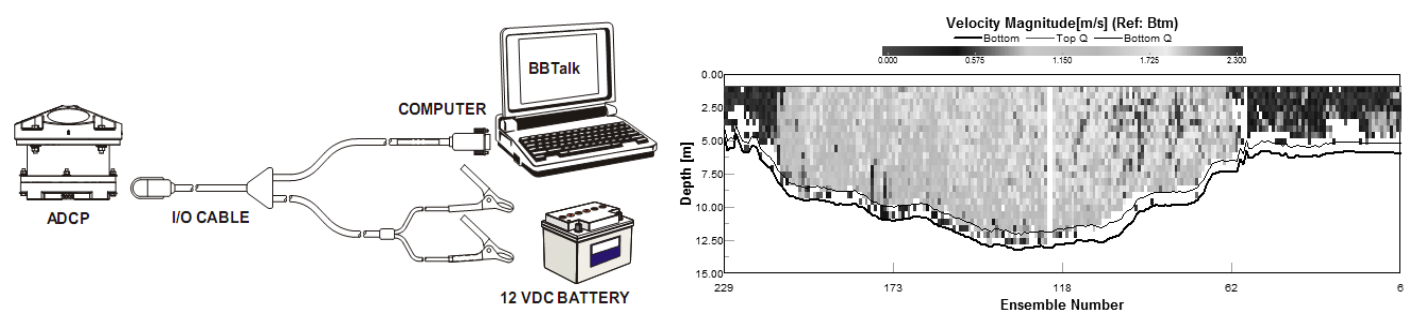

Figura 4: a) Conexões do ADCP Rio Grande (Teledyne RD Instruments, 2007) e b) medida real in loco da vazão extrema em Porto Grande - abril de 2011. 
ou mesmo verticais inteiras (lost ensembles ou bad ensembles). Quando isso ocorre, as vazões nestas células e verticais são estimadas por interpolação das células ou verticais mais próximas (Mueller e Wagner, 2009).

Em Porto Platon (P8), na quantificação da descarga líquida do dia 14 de abril, a maior vazão obtida foi de $4.036,67 \mathrm{~m}^{3} / \mathrm{s}$, às $17: 37 \mathrm{~h}$ (Figura 5 ). $\mathrm{Na}$ estação de Capivari (PCD1) a vazão foi de $1.566 \mathrm{~m}^{3} / \mathrm{s}$, no dia 15/04/2011. Na estação de Serra do Navio as medições foram de $1.183,75 \mathrm{~m}^{3} / \mathrm{s}$ nas primeiras medições, e, após a chuva ocorrida no local, a vazão medida foi $1.219,93 \mathrm{~m}^{3} / \mathrm{s}$, em 16/04/2011.

\subsection{Características do BRAMS Operacional NHMET- IEPA/CCAM-UNIFAP}

De acordo com Kuhn et al. (2010) o sistema de previsão do Amapá (NHMET/IEPA-CCAM-UNIFAP) tem por objetivo providenciar prognósticos numéricos para o Estado, e para este fim faz uso da versão 4.2 do BRAMS, versão disponível em http://brams.cptec.inpe.br.

Para cobrir a totalidade espacial da região estão sendo usadas duas rotinas operacionais assimilando dados disponibilizados pelo CPTEC/INPE. A área de abrangência do modelo compreende o retângulo com origem em $1,5 \mathrm{~S}-56 \mathrm{~W}$ até $4,5 \mathrm{~N}-46 \mathrm{~W}$, correspondendo a 250 pontos de longitude e 160 de latitude com espaçamento em $5 \mathrm{~km} \mathrm{x} 4 \mathrm{~km}$, respectivamente, com 32 níveis verticais, dos quais sete são em profundidades no solo. Os parâmetros de superfície como tipo de solo, vegetação, NDVI, temperatura da superfície do mar (TSM ou SST- Sea Surface Temperature), etc, são os mesmos recomendados e disponibilizados pelo sítio de Internet acima citado. $\mathrm{O}$ motivo do uso da referida grade é ótima relação custo computacional $\mathrm{x}$ resolução espaço-temporal. A configuração do cluster computacional está representada na Tabela 1 .
A Tabela 1 mostra o conjunto de opções do modelo em sua versão 4.2, empregada pela REMETAP/NHMET-IEPA/ CCAM-UNIFAP. As opções disponíveis no modelo em uso foram assinaladas com a letra $\mathrm{X}$, podendo haver alterações a partir do momento em que for notada variação significativa positiva (Kuhn, et al. 2010).

O BRAMS é um modelo numérico desenvolvido para simular a circulação atmosférica em várias escalas, com a capacidade de resolver um sistema de equações não hidrostáticas e compressíveis, conforme Tripoli e Cottom (1982). Para tanto, o modelo permite trabalhar com múltiplas grades aninhadas em pilhas ou em mosaicos, resolvendo as equações simultaneamente, permitindo a total integração entre elas e proporcionando um aumento da resolução espacial, conforme Freitas et al. (2009).

A parametrização do BRAMS para os processos físicos, como os de troca entre atmosfera e superfície, processos turbulentos, convectivos, radiativos e de microfísica de nuvens, foi resolvida pelo modelo, inclusive as características de esquema de cúmulos rasos e profundos baseados em uma aproximação do fluxo de massa (Grell e Denvenyi, 2002), bem como a utilização de umidade do solo com variação diária (Geaverd e Freitas, 2006).

De acordo com Kuhn et al. (2010) a parametrização da energia cinética turbulenta na Camada Limite Planetária (CLP) e vários outros biofísicos, como as de vegetação e solo para as regiões tropical e sub-tropical brasileiras e seus biomas, foram incorporados ao modelo. Além disto, o mapa de uso da terra é oriundo do projeto PROVEG (Sestini et al., 2003), enquanto os dados relativos aos tipos de solos brasileiros são resultantes do projeto RADAMBRASIL (Rossato et al., 2002). Os dados de Índice de Vegetação Normalizado por Diferenças (NDVI) são derivados do Moderate Resolution Imaging Spectroradiometer (MODIS), obtidos do período entre 2001 e 2002, processados

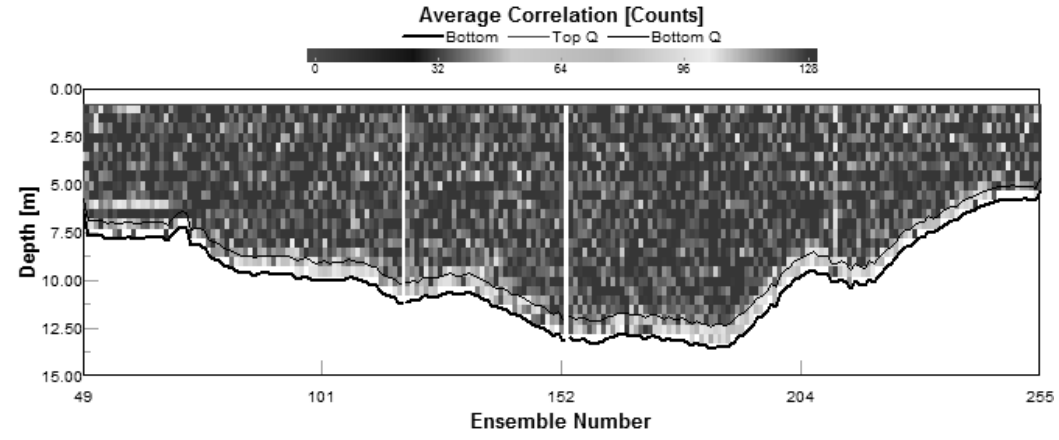

Figura 5: Medidas de descarga líquida recorde no dia do evento extremo em 14 de abril de 2011. Local: estação fluviométrica de Porto Platon (P8), no rio Araguari-AP. Descarga líquida: vazão de topo Qtopo $=333,506\left(\mathrm{~m}^{3} / \mathrm{s}\right)$, vazão efetivamente medida, Qmedida $=3.336,375\left(\mathrm{~m}^{3} / \mathrm{s}\right)$, vazão de fundo, Qfundo =331, $619\left(\mathrm{~m}^{3} / \mathrm{s}\right)$, vazão na margem esquerda, Qesq =26,530 (m³/s), vazão margem direira, Qdir $=8,643\left(\mathrm{~m}^{3} / \mathrm{s}\right)$. Vazão Total Qtotal $=4.036,672\left(\mathrm{~m}^{3} / \mathrm{s}\right)$. 
Tabela 1: Categorias e opções em uso do BRAMS - NHMET/IEPA-UNIFAP/REMETAP.

\begin{tabular}{|c|c|c|}
\hline Categoria & Opções & Em Uso \\
\hline Equações Básicas & Não-Hidrostática - compressível & $\mathrm{X}$ \\
\hline \multirow[t]{3}{*}{ Dimensão } & $1 \mathrm{D}$ & \\
\hline & $2 \mathrm{D}$ & \\
\hline & $3 \mathrm{D}$ & $\mathrm{X}$ \\
\hline \multirow[t]{2}{*}{ Coordenadas verticais } & Cartesiana & \\
\hline & $\begin{array}{l}\text { Seguindo o terreno } s_{z} \\
\text { ShavedEta }\end{array}$ & $\mathrm{X}$ \\
\hline \multirow[t]{2}{*}{ Coordenadas horizontais } & Cartesiana & \\
\hline & Estereográfica tangente ao plano & $\mathrm{X}$ \\
\hline \multirow[t]{3}{*}{ Grade-estrutura e deslocamento } & Grade $\mathrm{C}$ de Arakawa - uma grade (fixa) & $\mathrm{X}$ \\
\hline & $\begin{array}{l}\text { Grade } \mathrm{C} \text { de Arakawa - múltiplas grades } \\
\text { aninhadas (fixas) }\end{array}$ & \\
\hline & $\begin{array}{l}\text { Grade } \mathrm{C} \text { de Arakawa - múltiplas grades } \\
\text { aninhadas (móveis) }\end{array}$ & \\
\hline \multirow[t]{2}{*}{ Diferenciação finita no tempo } & $\begin{array}{l}\text { Centrado no tempo (Leapfrog); de } 2 \mathrm{a} \text { ordem de } \\
\text { precisão espacial }\end{array}$ & $\mathrm{X}$ \\
\hline & $\begin{array}{l}\text { Adiantado no tempo (Forward); de } 2 \mathrm{a} \text { ordem de } \\
\text { precisão espacial. }\end{array}$ & $\mathrm{X}$ \\
\hline \multirow[t]{4}{*}{ Fechamento da Turbulência } & Deformação K de Smagorinsky para a horizontal e & \\
\hline & Mellor e Yamada na vertical & $\mathrm{X}$ \\
\hline & O’Brien K / Blackadar K & \\
\hline & Deardorff nível 2.5 & \\
\hline \multirow[t]{2}{*}{ Precipitação estável } & Sem condensação & \\
\hline & Condensação & \\
\hline \multirow[t]{2}{*}{ Parametrização de Cumulus } & Desativada & \\
\hline & $\begin{array}{l}\text { Kuo modificado (Tremback,1990 apud Kuhn et al } \\
\text { (2010) }\end{array}$ & $X$ \\
\hline \multirow[t]{6}{*}{ Microfísica Explícita } & Desativada & \\
\hline & Microfísica para nuvens quentes & $\mathrm{X}$ \\
\hline & Microfísica de nuvens frias- & \\
\hline & Nucleação especificada & \\
\hline & Microfísica de nuvens frias - & \\
\hline & Nucleação prognósticada & \\
\hline \multirow[t]{9}{*}{ Radiação } & Desativada & \\
\hline & Onda Curta I - Chen & \\
\hline & Onda Curta II - Mahrer e Pielke & \\
\hline & Onda Curta III - Harrington & \\
\hline & Onda Curta IV - CARMA & $\mathrm{X}$ \\
\hline & Onda Longa I - Chen & \\
\hline & Onda Longa II - Mahrer e Pielke & \\
\hline & Onda Curta III - Harrington & \\
\hline & Onda Curta IV - CARMA & $\mathrm{X}$ \\
\hline Camada Superficial & Louis (1979) apud Kuhn et al (2010) & $\mathrm{X}$ \\
\hline \multirow[t]{2}{*}{ Fronteira Inferior } & $\begin{array}{l}\text { Especifica as diferenças de temperatura e umidade } \\
\text { entre a superfície e o ar } \\
\text { Diagnostica os fluxos de umidade e temperatura } \\
\text { baseado no modelo de solo }\end{array}$ & \\
\hline & Parametrização da Vegetação & $\mathrm{X}$ \\
\hline \multirow[t]{5}{*}{ Fronteira Superior } & Topo rígido & $\mathrm{X}$ \\
\hline & Prognóstico da pressão à superfície & $\mathrm{X}$ \\
\hline & Superfície Material & \\
\hline & Condição radiacional para onda de gravidade & \\
\hline & Camada de fricção Rayleigth & $\mathrm{X}$ \\
\hline \multirow[t]{5}{*}{ Fronteira Lateral } & Condição de fronteira radiativa I - & \\
\hline & Orlanski (1976) apud Kuhn et al (2010) & $\mathrm{X}$ \\
\hline & Condição de fronteira radiativa II - Klemp e & \\
\hline & Wilhelmson (1978 a, b) apud Kuhn et al (2010) & \\
\hline & $\begin{array}{l}\text { Condição de fronteira radiativa III - Klemp e Lilly } \\
\text { (1978) apud Kuhn et al (2010) }\end{array}$ & \\
\hline
\end{tabular}


pelo "Terrestrial Biophysics and Remote Sensing Lab" (http:// tbrs.arizona.edu).

De acordo com Kuhn et al. (2010), o BRAMS é constituído de um conjunto de vários módulos, cada um com suas características. É necessário que os parâmetros de entrada do modelo, bem como, os dos modelos acoplados, estejam listados em um arquivo de entrada chamado de RAMSIN. Este arquivo é necessário para as fases de execução do modelo, ou seja, as primeiras estruturam as condições das fronteiras inferior, superior e laterais da área de estudo, e a última fase é quando o modelo é executado para gerar os prognósticos finais.

\subsection{Método de Gumbel - análise de eventos de máximas vazões com base em séries}

A distribuição de Gumbel para eventos extremos de máximas vazões é a mais usada na análise de frequência de variáveis hidrológicas, principalmente na previsão de vazões de enchentes e na determinação da relação intensidade-duraçãofrequência das precipitações extremas (Naghettini e Pinto, 2007; Hartmann et al., 2011; Mujere, 2011). No presente caso, esta distribuição pode ser representada por um conjunto $\mathrm{Y}$, definido como a série de máximas vazões mensais medidas na Estação Porto Platon (Código 30400000) (ANA, 2013), e a função probabilidades acumuladas da distribuição de Gumbel é dada por:

$$
F_{y}(y)=\exp \left[-\exp \left(-\frac{y-\beta}{\alpha}\right)\right],
$$

para -oo $<y<00$. $-\mathrm{oo}<\beta<\mathrm{oo}, \alpha>0$, onde $\alpha$ representa o parâmetro de escala e $\beta$ é o parâmetro de posição. Segundo Naghettini e Pinto (2007), $\beta$ é a moda de Y. A função densidade de distribuição de Gumbel é:

$$
f_{y}(y)=\frac{1}{a} \exp \left[-\frac{y-\beta}{a} \exp \left(-\frac{y-\beta}{\alpha}\right)\right],
$$

e a variância de Y é dada por:

$$
\operatorname{Var}[Y]=\sigma_{Y}^{2}=\frac{\pi^{2} \alpha^{2}}{6} .
$$

A série histórica da Estação Porto Platon (P8) para as vazões máximas foi gerada a partir de medições diárias, no período de janeiro/1952 a agosto/1958 e de junho/1972 e março/2013. Neste trabalho foram considerados apenas os dados até março/2011, mês anterior ao evento extremo com o objetivo de testar a série antes deste evento. No presente caso, o valor de $\beta$ foi obtido pela moda das vazões máximas e $\alpha$, pela variância segundo a equação 3 .

A partir da análise dos dados de vazão medidos com o ADCP na estação de Porto Platon, entre os dias 14 e 15 de abril de 2011, foi elaborada uma análise comparativa da série histórica registrada pelo sistema Hidroweb (ANA, 2012) com a distribuição de Gumbel e estimado para o período de retorno (1/(1-FY(y)) das vazões, conforme Naghettini e Pinto (2007).

\section{RESULTADOS E DISCUSSÃO}

\subsection{Reanálise com uso do modelo numérico de previsão BRAMS}

De acordo com a re-análise efetuada no modelo de previsão do tempo BRAMS, foram estimadas chuvas intensas sobre a área de drenagem da bacia a montante da estação de Porto Platon (P8). De acordo com o modelo BRAMS as precipitações variaram de $30 \mathrm{~mm}$ a $140 \mathrm{~mm}$ diários entre os dias 7 e 11 de abril (Figuras 6a-6e). Também foi possível identificar picos de máximas precipitações mais evidentes durante os dias 9 e 10 de abril de 2011, intervalo em que foram registradas as vazões máximas recordes.

Ainda nas Figuras 6a-6e, os resultados numéricos indicaram precipitação intensa oscilando em torno de $140 \mathrm{~mm}$ sobre a cabeceira do rio Araguari. Mas estas precipitações intensas também se distribuíram ao longo do extremo norte da bacia, mais precisamente entre as cabeceiras dos rios Araguari e Falsino (Figura 1). Este resultado segue o padrão de distribuição médio da precipitação na bacia, conforme configuração representada pela Figura 3 (Oliveira et al., 2010). De acordo com o modelo, observa-se que neste mesmo dia 10 de Abril houve precipitação intensa que variou entre $50 \mathrm{~mm}$ e $140 \mathrm{~mm}$ durante o início da madrugada, ao norte da bacia.

$\mathrm{Na}$ saída numérica do modelo BRAMS as chuvas sobre a área das nascentes iniciaram no decorrer do dia 07 de abril, variando entre $20 \mathrm{~mm}$ e $30 \mathrm{~mm}$ na área localizada sobre o afluente principal (rio Amapari) da bacia do Araguari, aumentando em intensidade e amplitude no decorrer do dia (Figura 6a). No dia seguinte, 08 de abril, o modelo indicou que as precipitações se estenderam por toda a área norte da bacia, englobando os três principais cursos, o rio Amapari (à oeste), o trecho superior do rio Araguari (no centro) e o rio Falsino (ao norte), com variações de $20 \mathrm{~mm}$ a $50 \mathrm{~mm}$ (Figura 6b). No decorrer do dia 9 de abril, o modelo indicou uma distribuição de chuvas sobre os divisores de águas da bacia, com acúmulos de até $60 \mathrm{~mm}$ (Figura $6 \mathrm{c}$ ). No dia 10, as chuvas previstas se propagaram por mais da metade da área da bacia, com variações de $30 \mathrm{~mm}$ a $140 \mathrm{~mm}$, estendendo-se desde o centro da bacia até o extremo norte da mesma (Figura 6d). No dia 11 de abril as chuvas se estenderam por mais de $75 \%$ da área total de drenagem da bacia. Nesta data, os picos alcançaram até $90 \mathrm{~mm}$ na região oeste, mais precisamente na zona de drenagem do rio Amapari (Figura 6e). A partir do dia 12 de abril houve diminuição significativa de precipitação, contudo, ainda abrangendo uma significativa área da bacia, na parte sudoeste, com máximos de até 24mm (Figura 6f). 

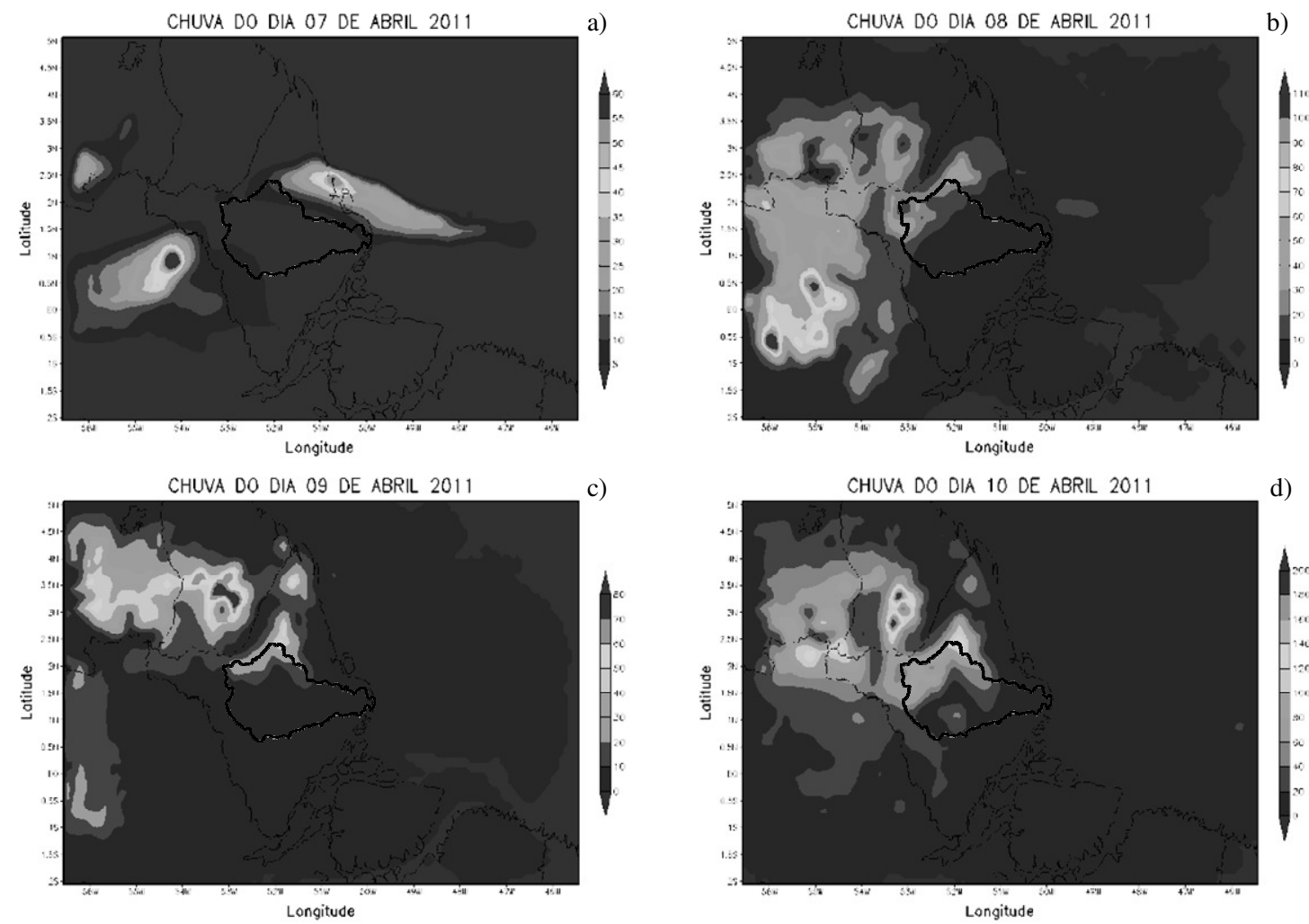

c)
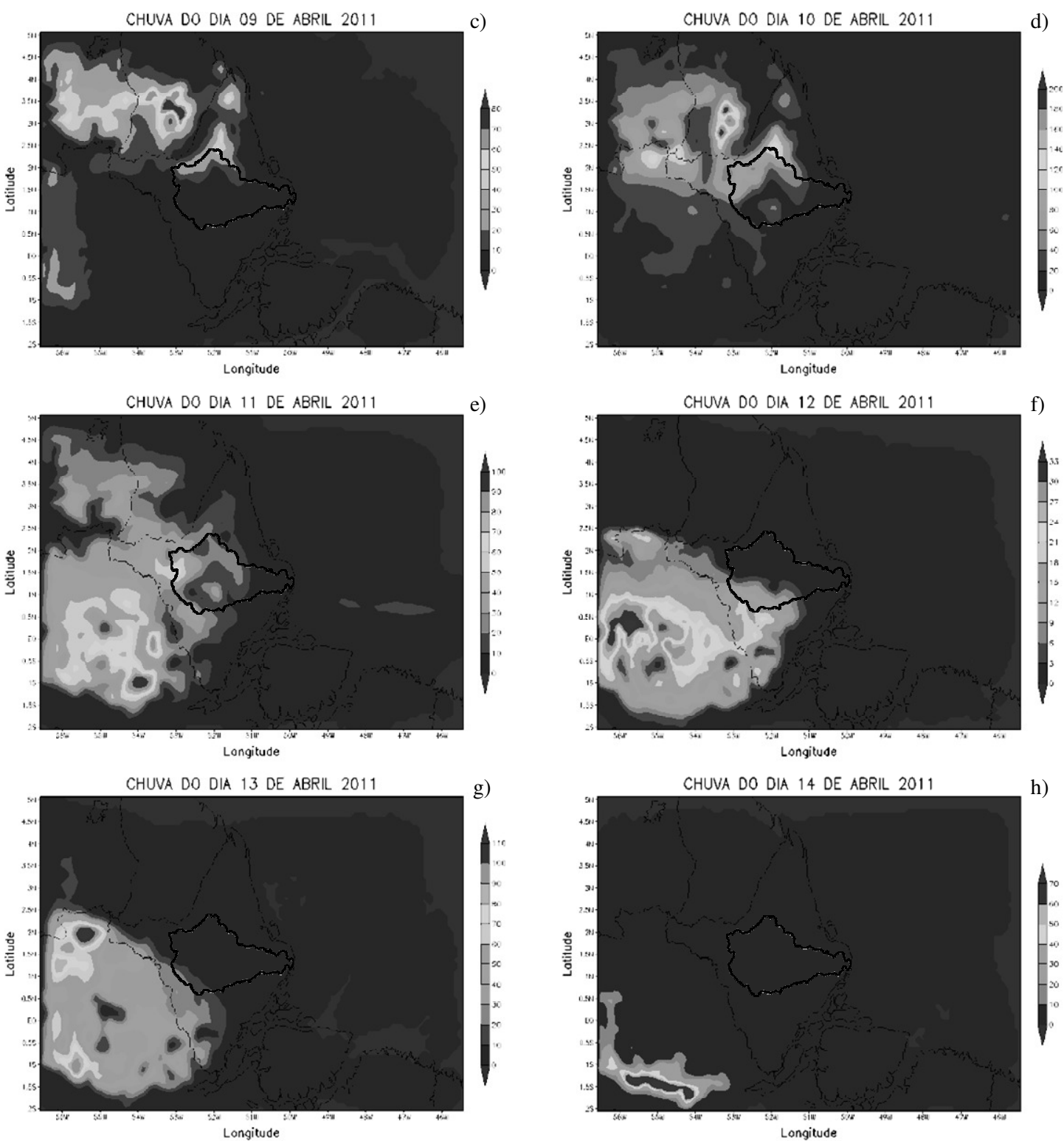

Figura 6: Saídas de precipitação diária total do modelo BRAMS-AP/NHMET-IEPA/CCAM/UNIFAP. Dias próximos e durante o evento extremo para toda a bacia do rio Araguari-AP, destacada pela linha preta poligonal no centro (07-14/04/2011). 
O modelo BRAMS indicou que as chuvas intensas cessaram apenas no dia 13 de abril, quando os sistemas de grande escala se dissiparam. Contudo, foi possível observar que chuvas de menor intensidade, mas de grande extensão, se mantiveram em praticamente todo o Estado do Amapá e ao longo de todo o período estudado (Figura 6g). Além disso, chuvas intensas também foram estimadas pelo modelo meteorológico até o dia 20 de abril. Estas estenderam-se por até $75 \%$ do total da área da bacia e alcançando máximos de $70 \mathrm{~mm}$, principalmente nas áreas de nascentes dos rios que compõem a Bacia do rio Araguari (Figura 6h). Contudo, observa-se ainda ocorrências, no período precipitações em pequena escala, do tipo "pancadas de chuvas localizadas". Estas, apesar de ocorrerem em pequena escala (da ordem de poucos quilômetros), são capazes de precipitar grandes volumes de água, alcançando até $40 \mathrm{~mm}$ em meia hora.

Em relação aos cenários executados pelo PBMC (2012) o ciclo sazonal das chuvas é afetado pelas variações interanuais, que podem produzir alterações no ciclo de chuvas, como, por exemplo, a ocorrência de seca durante a estação chuvosa, ou mesmo uma estação chuvosa abundante demais. Uma importante fonte de variabilidade interanual são os eventos El Niño e La Niña e o Dipolo Positivo/Negativo Atlântico Norte (Souza e Cunha, 2010).

Em termos de precipitação, recentes pesquisas do PBMC (2012) mostram as seguintes tendências para a Amazônia: reduções percentuais de $10 \%$ na distribuição de chuva e aumento de temperatura de $1^{\circ}$ a $1,5^{\circ} \mathrm{C}$ até 2040 , mantendo a tendência de diminuição de $25 \%$ a $30 \%$ nas chuvas e aumento de temperatura entre $3^{\circ}$ e $3,5^{\circ} \mathrm{C}$ no período $2041-2070$, e redução nas chuvas de $40 \%$ a $45 \%$ e aumento de $5^{\circ}$ a $6^{\circ} \mathrm{C}$ na temperatura no final do século (2071-2100). Entretanto, pelo menos em relação ao período atual, esta tendência não corrobora com os resultados obtidos na presente investigação. No presente caso há nítido aumento de eventos extremos de chuva-vazão em detrimento dos de seca (ver por exemplo outliers da Figura 2). Uma explicação razoável seria a proximidade do Estado do Amapá com as grandes massas de água (Oceano e rio Amazonas) que sofrem interferências de grandes sistemas. Mas é também importante considerar as áreas de UCs "intocadas", que não permitem desmatamento ou apenas uso sustentado, diferentemente do que ocorre nas regiões centrais ou ao sul da Amazônia (arco de desmatamento) (Dias, 2013).

Ressalte-se que as previsões do PBMC (2012) são consideradas como de alta confiabilidade. Ou seja, a previsão de elevação da temperatura ( 1 a 5 oC, no verão e 1,5 a 6 oC, no inverno, ao longo deste século) e redução das precipitações (10 a 40\% no verão, e 10 a 45\%, no inverno, ao longo deste século) é significativamente maior nas áreas da Amazônia do que no Nordeste ou Mata Atlântica.
Entretanto, na escala local em nível de estado do Amapá, o presente evento de precipitação-vazão em tela parece sugerir uma tendência contrária à de PBMC (2012), no curto prazo. Por outro lado, em 2004 e 2005 também ocorreram secas extremas na bacia do rio Araguari, chegando a paralisar o setor hidrelétrico. Neste caso, o que se percebe é o aumento de eventos extremos aleatórios, tanto para cheias quanto para secas extremas, com prevalência dos primeiros. Com efeito, segundo as observações das vazões de 2011 no rio Araguari, as incertezas parecem se confirmar acerca dos impactos da distribuição da precipitação na Amazônia e suas respectivas consequências nos ciclos hidrológicos (Soito Junior e Freitas, 2011).

Estes fatos reforçam a hipótese da fragilidade do sistema de previsão na Amazônia, sendo talvez a baixa densidade de estações de observação de superfície uma das principais causas, onde frequentemente há séries históricas, que nem sequer contemplam um único período interdecenal ( $>8$ anos) (Blanco et al. 2007). Trata-se de caso de extrema deficiência e que põe em risco os usuários da bacia hidrográfica. Além disso, dificultam a quantificação de potenciais serviços ambientais hídricos e aumentam as incertezas dos balanços biogeoquímicos de interesse ecológico presentes em bacias hidrográficas (Kemmenes et al., 2008; Soito Junior e Freitas, 2011; Marins, 2013; Cunha et al., 2013; Cunha, 2013).

$\mathrm{Na}$ área da bacia do rio Araguari $(\approx 42 \mathrm{mil} \mathrm{km} 2)$, até a ocorrência do referido evento extremo, havia somente 4 estações fluviais monitorando o sistema hídrico, mostrando-se deficientes e frequentemente inoperantes (Figura 3), motivos provável pelos quais o evento hidrológico extremo investigado não tenha sido previsto pelo sistema de monitoramento disponível. Neste caso, apresentam-se duas dificuldades básicas: a) não há respostas hidrometeorológicas em escalas mais reduzidas (nível de bacia do estado do Amapá); b) tais respostas divergem razoavelmente das previstas pelo PBMC (2012) ou projeções para toda a Amazônia. Além disso, as divergências de tendências parecem ser também opostas em relação às flutuações de cheias e secas na Amazônia, em comparação com o nível de escala regional, tais como em bacias hidrográficas no Estado do Amapá (Neves et al., 2011).

\subsection{Análise sinótica}

De acordo com as imagens de satélite das Figuras 7a-7c), no decorrer do dia 09 de abril, observou-se nuvens baixas sobre toda a extensão da bacia do rio Araguari. Contudo, não se registrou sistemas intensos de precipitação durante o dia. Ao se aproximar do período noturno, houve desenvolvimento de aglomerados convectivos provenientes da região do Marajó e nordeste do Pará, associados a pulsos precipitantes da Zona de Convergência Intertropical (ZCIT) (Souza et al., 2009), 
desencadeando Linhas de Instabilidade (Cohen et al., 1989; Cohen et al., 1995) que se estendem desde a costa do Suriname até a ilha de Marajó, encobrindo praticamente todo o Estado do Amapá.

É possível observar que esse sistema formou aglomerados de precipitações intensas, principalmente entre as cabeceiras dos rios Falsino e Araguari. Este sistema teve início às $18 \mathrm{~h}$ UTC e término às $01 \mathrm{~h}$ UTC do dia 10 de abril, quando então houve a dissipação do mesmo. Estimou-se então um acumulado de precipitação próximos dos $200 \mathrm{~mm}$ em um período de aproximadamente 7 horas, considerado como muito intenso para este tipo de sistema.

No decorrer do dia 10 de abril não foi possível observar outros sistemas de precipitação intensos, além do ocorrido no início da madrugada. Mas foi possível observar sistemas precipitantes menos intensos no decorrer dos dias 11 a 20 de abril. Contudo, nenhum comparado ao ocorrido na noite do dia 09 e madrugada do dia 10. Além disso, foi observado que o "padrão" de distribuição das precipitações das Figuras 7a-7c) apresentou tendência semelhante ao da distribuição média da precipitação descrita por Oliveira et al. (2010) (Figura 3). Esse fato sugere uma possibilidade de combinar a modelagem numérica com dados sinóticos em estudos futuros, nos quais fenômenos hidrometeorológicos extremos sejam melhor interpretados.

\subsection{Breve análise para vazões máximas com uso do modelo de Gumbel}

Foi elaborada uma análise estatística simplificada da série histórica das vazões máximas mensais medidas na estação fluviométrica de Porto Platon (304000000), representada pelos parâmetros foram Qmédia $=1.314,14 \mathrm{~m} 3 / \mathrm{s}$; Erro Padrão $=$ 35,60; Mediana $=1.208,15 ;$ Moda $=265$; Desvio Padrão $=$ 841,02; Variância $=707.315,9$; Curtose $=-0,69$; Assimetria $=0,50 ;$ Intervalo $=3.730 ;$ Mínimo $=72 ;$ Máximo $=733.232$; Contagem $=558$.
Como resultado, foi obtido o parâmetro de posição da distribuição de Gumbel, $\beta$ igual a 265, o qual representou a moda da série analisada (Naghettini e Pinto, 2007). A variância da amostra obtida foi igual a 707.315,9 e, a partir da equação 3, o valor do parâmetro de escala, $\alpha$, foi igual a 665,74 . Com esses valores, e utilizando a equação 1 , a função de probabilidades acumuladas da vazão medida com o ADCP em Porto Platon no dia $14 / 04 / 2011\left(\mathrm{Qmax}=4.036 \mathrm{~m}^{3} / \mathrm{s}\right)$, foi estimado em 0,996795. A função de probabilidade acumulada, de acordo com a distribuição de Gumbel, foi a vazão medida superior a 99,68\% das vazões máximas esperadas para a seção de Porto Platon. Com efeito, o período de retorno para esta vazão extrema foi estimado em "312" anos, bastante elevado. Até o evento extremo de abril/2011, a maior vazão registrada na referida estação tinha sido de $\mathrm{Qmax}=3.802 \mathrm{~m} / \mathrm{s}$, em abril de 1974 (com período de retorno $=220$ anos).

Ressalte-se que esta máxima vazão medida pelo ADCP provavelmente seria menor do que a vazão extrema real de 2 a 3 dias anteriores à medição em campo com o $\mathrm{ADCP}(\mathrm{Qmax} \approx$ $4.036 \mathrm{~m} 3 / \mathrm{s}$. Tal constatação decorre da observação do nível d'água nas residências próximas à seção Porto Platon (P8), onde o nível do rio Araguari marcava valor mais elevado do que o observado pela vazão extrema real de dias anteriores. Assim, as vazões extremas efetivas entre os dias 10 e 15 de abril de 2011 não foram de fato registradas pelo sistema Hidroweb da ANA (2013). Além disso, a régua limnimétrica encontrava-se totalmente submersa durante o evento, notadamente entre os dias 10 e 13. Neste caso, estimou-se que a Qmax em relação ao recorde anterior foi provavelmente 6\% maior (Qmax estimada $\approx 4.278,16 \mathrm{~m} 3 / \mathrm{s}$ ).

Como pode ser observado na Figura 8 , houve um intervalo de tempo sem registro de vazões máximas em todas as três estações de monitoramento da bacia: Porto Platon (P8), Serra do Navio e Capivari. A única exceção foi o registro observado pela operação da barragem da UHCN. Ainda na Figura 8 verifica-se que, durante o evento, a única observação contínua da vazão ocorreu na própria barragem da UHECN (rio

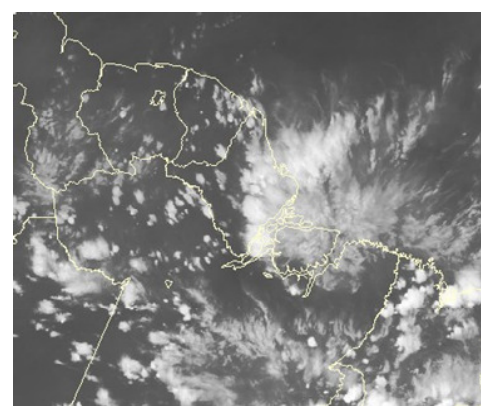

a) Dia $09-1800$ UTC

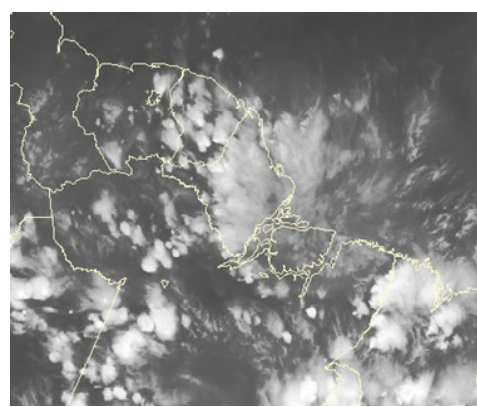

b) Dia $09-2100 \mathrm{UTC}$

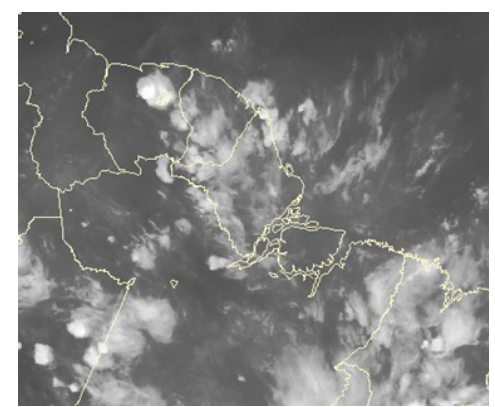

c) Dia 10 - 0000UTC

Figura 7: Imagens de satélite GOES-12 referente ao evento ocorrido na madrugada do dia 09 para o dia 10 de abril de 2011 sobre a bacia do rio Araguari-AP. 
Araguari - círculos). Entre o $40^{\circ}$ e o $44^{\circ}$. dia (a partir da data do início da análise) em todas as demais estações fluviométricas observou-se ausência de registro. Além do mais, observou-se a partir do $47^{\circ}$ dia que a estação Capivari (Araguari - triângulos) foi re-iniciada somente e logo após a ocorrência do evento extremo. Este fato parece revelar a fragilidade sistêmica dos objetivos do monitoramento hidrológico, o qual "perde" sua utilidade preventiva de proteção dos usuários da bacia hidrográfica.

Na Figura 8 é também possível observar uma co-variância entre os registros da estação de Serra do Navio (rio Amapari quadrados) e as do rio Araguari durante o evento extremo. Mas, neste caso, percebe-se também que a resposta das vazões em Porto Platon (rio Araguari - losângulos) dependem fundamentalmente das respostas simultâneas das estações Capivari (rio Araguari - triângulos) e Serra do Navio. Como os registros de Capivari encontravam-se inoperantes durante o evento, percebeu-se a deficiência das previsões de cheias nas referidas estações.

Assim, a presente investigação representa um avanço considerável sobre os processos hidrológicos da bacia do rio Araguari, revelando algumas das falhas do sistema de monitoramento hidrológico na escala adequada para os estudos de recursos hídricos, a bacia hidrográfica.

Por estas razões as deficiências do sistema e as falhas operacionais dos registros de dados tendem a interferir nas estimativas de previsões estratégicas para a bacia hidrográfica. As falhas apontadas mostram algumas das evidências ou prováveis causas as incertezas do clima apresentadas no início deste artigo, onde foram analisados vários estudos hidrológicos e climáticos da
Bacia Amazônica. A investigação mostrou também onde e como ocorrem esses problemas de incerteza. Futuramente, é necessário que seja melhorado todo o sistema de monitoramento de previsão de eventos hidrometeorológicos extremos do estado do Amapá, de modo que os usuários de bacias hidrográficas, especialmente as relacionados com o setor hidrelétrico e ambiental, como a do rio Araguari-AP e Jari-AP, tenham mais segurança em relação às tendências do clima no futuro e seus impactos sobre diversos setores da economia.

\section{CONCLUSÕES}

Foi analisado um evento extremo de máxima precipitaçãovazão na bacia do rio Araguari-AP durante o período chuvoso de 2011. As seguintes conclusões foram obtidas:

1) Verificou-se razoável eficiência do modelo BRAMS na previsão da precipitação durante o evento hidrometeorológico crítico, representando o padrão da sinótica de precipitação observada pode dados experimentais, onde os sistemas mais atuantes são as conhecidas ZCIT (Zonas de convergência intertropical) e as ZI (zonas de instabilidade). Mas o modelo tende a subestimar a intensidade das chuvas em relação às séries históricas sinóticas neste tipo de evento extremo.

2) As precipitações locais de curto prazo, tanto observadas quanto numéricas, tendem a divergir em relação às previsões climáticas gerais de mesoescala de longa duração. Por exemplo, as secas intensas em 2004/2005 e a cheia de 2011, na bacia do rio Araguari, sugerem que os eventos extremos são cada vez mais frequentes na bacia, com o agravante de que os sistemas

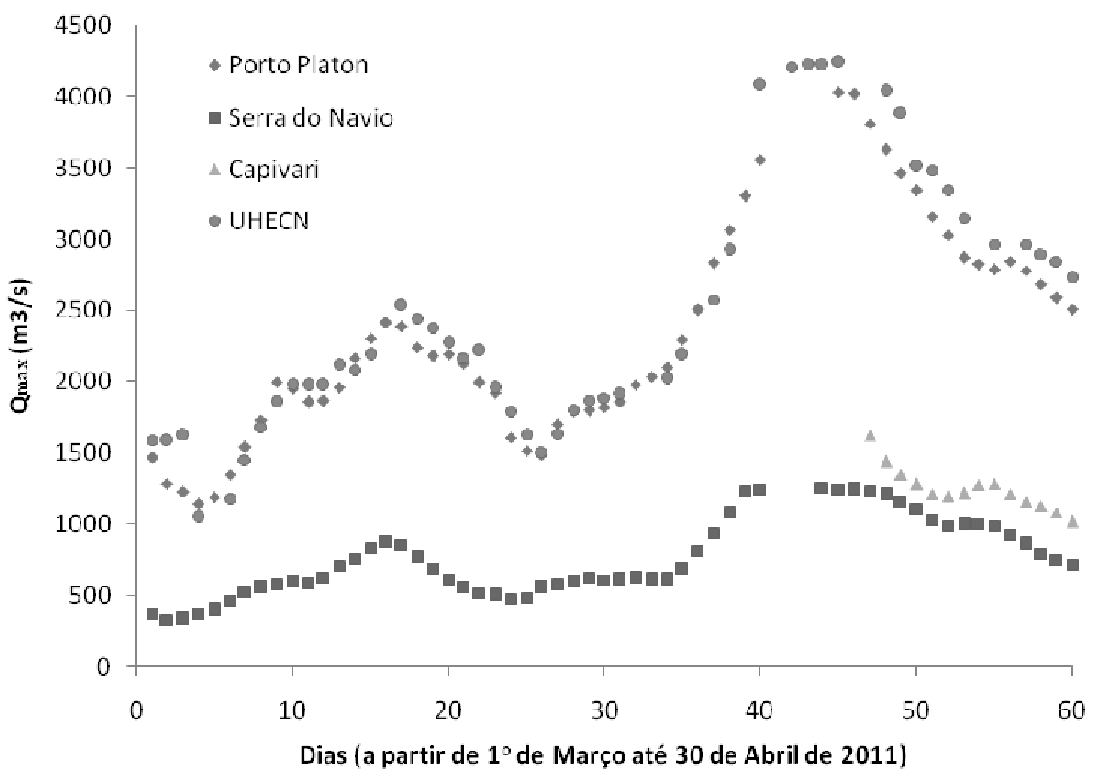

Figura 8: Resultados da vazão medida diária $(\mathrm{m} 3 / \mathrm{s})$ com base em dados fluviométricos das estações de Porto Platon, Serra do Navio e Capivari no período entre $1^{\circ}$. de Março a 30 Abril de 2011 - rio Araguari-AP. A barra vertical hachuriada indica intervalo de tempo sem registro das estações no momento crítico do evento extremo de vazão. 
controladores localmente são ainda pouco compreendidos. Portanto, as respostas hidrológicas sugerem insuficiência de informações e fragilidade do sistema de monitoramento e de previsão de fenômenos extremos de chuva-vazão.

3) A previsão em "tempo quase real" depende fundamentalmente de observações de curto prazo. Assim, percebeu-se que a ausência de estações nas cabeceiras dos rios Araguari, Falsino e Amapari tende comprometer a análise do comportamento e respostas hidrológicas no seu médio curso e a jusante. Este fato, portanto, confirma a necessidade de adensamento de estações na bacia (principalmente as automáticas - PCDs), de modo a criar um ciclo virtuoso de retroalimentação de dados no sistema de observação versus previsão. Esta providência deve otimizar todo o sistema de gestão hídrica na bacia.

4) As deficiências infraestruturais de observação dificultam ações preventivas e aumentam os riscos das ações tardias ou reativas no enfrentamento de problemas hidrológicos na bacia. As séries diárias de vazões, além de apresentarem constantes interrupções de monitoramento, fracionando o conjunto das observações, geram uma falsa impressão que as mesmas estão fornecendo "segurança" ao sistema de prevenção. Mas, de fato, tais falhas podem gerar mais incertezas nas previsões em caso de eventos extremos.

5) Finalmente, o estudo revelou que a vazão recorde registrada indicou que a previsão em "tempo quase real" não tem cumprido com seu papel preventivo a eventos extremos. Deste modo, evidencia-se a falta de parâmetros confiáveis para estudar a dinâmica de previsão de eventos extremos futuros na bacia do rio Araguari. É importante também ressaltar que as falhas observadas no sistema de monitoramento, para o referido evento extremo, poderiam apresentar graves consequências aos usuários da bacia. Setores que foram mais afetados, como o de operação hidrelétrico, o ambiental e o da defesa civil, apresentaram vulnerabilidade sistêmica da previsão. De qualquer modo, os usuários da bacia devem incorporar novas medidas de adaptação frente às demandas socioambientais e às mudanças climáticas globais em curso. Isto exigirá, por exemplo, gestão mais integrada entre reservatórios de usinas hidrelétricas contíguas na bacia, além de uma visão mais ampla dos múltiplos usos da água. Tais medidas de adaptação ao clima representam um esforço necessário e considerável na constituição de sistemas gerenciais de bacias hidrográficas no Estado do Amapá.

\section{AGRADECIMENTOS}

Pelo suporte financeiro referentes às diversas etapas de investigação experimentais e numéricas: Projeto REMAM2" - Eventos Extremos (convênio nº 0109057300/FINEP), ao CNPq (Processo 475614/2012-7), Projeto "Modelagem hidrodinâmica e qualidade da água no Estuário do baixo rio Araguari, AP; Projeto INCT/CENBAM (Convênio $n^{\circ}$ 722069/2009) Biodiversidade da Amazônia e Projeto Trocas: "Net Ecossystem exchange of the Lower Amazon: from land to the Ocean and atmosphere", Processo FAPESP no $\neg$ 12/51187-0.

\section{REFERÊNCIAS BIBLIOGRÁFICAS}

ALEXANDRE, A. M. B; SOUZA FILHO, F. A; CAMPOS, J. N. B. Incorporação do Impacto da Rede de Reservatórios Superficiais Artificiais de Caráter Intranual na Modelagem Hidrológica Chuva-Vazão. Revista Brasileira de Recursos Hídricos. v.18 n.2, p. 67-82, 2013.

ANA, 2012. Agência Nacional de Águas [WWW Document]. Hidroweb. URL http://hidroweb.ana.gov.br/. 2012.

ANA. Agência Nacional de Águas. Disponível em: <http:// hidroweb.ana.gov.br/>. Acesso em: 27 ago. 2013.

BLANCO, C. J. C; SECRETAN, Y. FAVRE, A. C. Análise, Aplicação e Transposição de um Modelo Chuva-Vazão para Simulação de Curvas de Permanência de Pequenas Bacias da Amazônia. Revista Brasileira de Recursos Hídricos, v. 12 n. 1, p. 205-216, 2007.

BRAMS/CPTEC. Centro de Previsão de Tempo e Estudos Climáticos. Disponível em: <http://brams.cptec.inpe.br/> Acesso em: 04 Set. 2009, 10:30:00.

COHEN, J. C. P; SILVA DIAS, M. A. F.; NOBRE, C. A. Aspectos climatológicos das linhas de instabilidade na Amazônia. Climanalise. v. 4 n. 11, p.34-40, 1989.

COHEN, J. C. P.; SIlva DIAS. M. A. F; NOBRE, C. A. Environmental conditions associated with Amazonian squall lines: a case study. Monthly Weather Review, v. 123, n. 11, p. 3163-3174, 1995.

CUNHA, A. C. Revisão descritiva sobre ecossistemas aquáticos na perspectiva da modelagem da qualidade da água. Biota Amazônia, Artigo de Revisão.v. 3, n. 1, 2013. p. 124-143.

CUNHA, A. C. et al. Dam Effect on Stream Reaeration Evaluated with the Qual2kw Model: Case Study of the Araguari River, Amazon Region, Amapá State/Brazil. In: Hensel, Jeferson Francisco Selbach e Carolina Bilibio CDU Chemical Tecnhology. (Org.). Book Sustainable Water Management in the Tropics and Subtropics - And Case Studys in Brazil-Technics: Energy, Industry, Sewage, Waste, Waste Water, Chemistry, Toxicology and GIS. 1ed. Jaguarão/ RS /UniKassel: Fundaç: Fundação Univ. Fed. do Pampa, UNIKASSEL, PGCult-UFMA, v. 2, 2011. p. 150-174.

CUNHA, A. C.; PINHEIRO, L. A. R.; CUNHA, H. F. A. Modelagem e simulação do escoamento e dispersão sazonais de agentes passivos no Rio Araguari para o AHE Ferreira 
Gomes-I- Amapá/Brasil. Revista Brasileira de Recursos Hídricos (RBRH), v. 18, n. 1, Jan/Mar. 2013. p.34-51.

DIAS, T. C. A. de C. Unidades de Conservação brasileiras: investimentos, custos de manejo e potencialidades econômicas. Tese (Doutorado), Universidade Federal do Amapá - UNIFAP/PPGBio, Macapá-AP. 2013.

DINEHART, R. L.; BURAU, J. R. Repeated surveys by acoustic Doppler current profiler for flow and sediment dynamics in a tidal river. Journal of Hydrology, v. 314, p. 1-21, 2005.

ELETRONORTE. Estudos de Inventário Hidrelétrico, Bacia Hidrográfica do Rio Araguari, Estado do Amapá. Relatório Final. 1999.

FIGUEROA, S. N.; NOBRE, C. A. Precipitation distribution over central and western tropical South America. Climanálise, v. 5, n. 6, 1990. p.36-45.

FREITAS, S. R., K. M. et al. The Coupled Aerosol and Tracer Transport model to the Brazilian developments on the Regional Atmospheric Modeling System) CATTT-BRAMS - Part 1: Model description and evaluation. Atmospheric Chemistry and Physics, 9, 2009. p. 2843-2861.

GEAVERD, R.; S. R. FREITAS. Estimativa operacional da umidade do solo para iniciação de modelos de previsão numérica da atmosfera. Parte 1: Descrição da metodologia e validação. Revista Brasileira de Meteorologia, v. 21, n. 3, p. 1-15, 2006.

GRELL, G.; DEVEANY, D. A generalized approach to parameterizing convection combining ensemble and data assimilation techniques. Geophysical Research Letters, v. 29, n. 14., doi: 10.1029/2002GL015311, 2002.

HARTMANN, M.; MOALA, F. A.; MENDONÇA, M. A. Estudo das precipitações máximas anuais em Presidente Prudente. Revista Brasileira de Meteorologia, v. 26, n. 4, p. 561-568, 2011.

KEMMENES, A; FORSBERG, B.; MELACK, J. As hidrelétricas e o aquecimento global. Ciência Hoje. v. 41, n. 245, p. 20-25, 2008.

KUHN, P.; CUNHA, A. C.; PEREIRA, M. J.; SARAIVA, J. M. B. Previsão Numérica Operacional no Estado do Amapá utilizando o BRAMS. In: CUNHA, A. C.; SOUZA, E. B. de; CUNHA, H. F. A. (Eds.). Tempo, Clima e Recursos Hídricos - Resultados do Projeto REMETAP no Estado do Amapá. 1 ${ }^{\mathrm{a}}$. ed. Macapá: IEPA, p. $61-82,2010$.

LOPES, M. N. G. Aspectos regionais da variabilidade de precipitação no Estado do Pará: estudo observacional e modelagem climática em alta resolução. Dissertação de Mestrado, Universidade Federal do Pará/ Faculdade de Meteorologia/ Programa de Pós-Graduação em Ciências Ambientais. Belém-PA. 2009. 80p.
MARINS, J. Vem aí energia suja. Horizonte Sustentável. Revista Horizonte Geográfico, v. 145, p. 56-63, 2013.

MENDIONDO, E. M. e TUCCI, C. E. Escalas hidrológicas. I. Conceitos. Revista Brasileira de Recursos Hídricos, v. 2, n.2, Jul/Dez 1997. p. 21-44.

MUELLER, D.S., WAGNER, C. R. Measuring Discharge with Acoustic Doppler Current Profilers from a Moving Boat. In: U.S. Geological Survey Techniques and Methods 3A- 22. Virginia, 2009. 72p.

MUJERE, N. Flood Frequency Analysis Using the Gumbel Distribution. International Journal on Computer Science and Engineering, v. 3, n. 7, 2011. p. 2774-2778.

MUSTE, M., YU, K., SPASOJEVIC, M. Practical aspects of ADCP data use for quantification of mean river flow characteristics; Part I: moving-vessel measurements. Flow Measurement and Instrumentation 15, 2004. p. 1-16.

NAGHETTINI, M; PINTO, E. J. A. Hidrologia Estatística. Serviço Geológico do Brasil -CPRM, Agosto 2007. 600 p. NEVES, D. G.; CUNHA, A. C.; SOUZA, E. B. de; BARRETO, N. J. C. Modelagem climática regional durante dois anos de extremos de precipitação sobre o Estado do Amapá: Testes de sensibilidade aos esquemas convectivos. Revista Brasileira de Meteorologia, v.26, n.4, 2011.p. 287 - 294.

OLIVEIRA, L. L, CUNHA, A.C., JESUS, E. S. e BARRETO, N. J. C. Características Hidroclimáticas da Bacia do Rio Araguari-AP. In: Tempo, clima e recursos hídricos: resultados do Projeto REMETAP no Estado do Amapá. CUNHA, A.C., SOUZA, E.B. de; e CUNHA, H.F.A, (Coord). Macapá : IEPA, 2010. 216 p.

PAINEL BRASILEIRO DE MUDANÇAS CLIMÁTICAS (PBMC). Base Científica das Mudanças Climáticas. Contribuição do Grupo de Trabalho 1 para o $1^{\circ}$. Relatório de Avaliação Nacional do Painel Brasileiro de Mudanças Climáticas. [Ambrizzi, T., Araújo, M., Silva Dias, P.L.,Wainer, I., Artaxo, P., Marengo, J.A.]. Sumário Executivo do Volume 1,PBMC, Rio de Janeiro, Brasil, 2012. 34 p.

PESSOA, C. L.; BLANCO, J. C.; MARTINS, J. R. Simulação hidrológica de rios com grandes planícies de inundação. Revista Brasileira de Recursos Hídricos, v. 15, n. 4, 2011. ROSSATO, L. R.; ALAVALÁ, E.; TOMASELLA, J. Climatologia da umidade do solo no Brasil. Anais... XII Congresso Brasileiro de Meteorologia, 2002. p. 1910-1915.

SANTOS, E. S. Modelagem hidrodinâmica e qualidade da água na foz do Rio Araguari -AP. Dissertação de Mestrado em Biodiversidade Tropical PPGBIO/Universidade Federal do Amapá. 2012. 108p.

SESTINI, M. et al. Mapa de cobertura da terra da Amazônia legal para uso em modelos meteorológicos. Anais... XI Simpósio Brasileiro de Sensoriamento Remoto, p. 29012906, 2003. 
SHATFIELD, C. The analysis of the time series.An introduction.Sixth Edition.Chapman \& Hall/CRC. 2004. $333 p$.

SILANS, A. M. B. P; ALMEIDA, C. N; PORTO, R.Q. Impacto da incerteza na representatividade da repartição espacial da precipitação sobre os hidrogramas e as curvas de permanência obtidos de um modelo chuva-vazão distribuído. Revista Brasileira de Recursos Hídricos, v. 14, n. 2, p. 59-71, 2009.

SOITO JUNIOR, M.; FREITAS. A. Hydroenergy Expansion in the Brasil: vulnerability, impacts e potential adaptations to climatic changes. Renewable Energy Reviews, v. 15, p. 3165-3177, 2011.

SOUZA, E. B. de; CUNHA, A. C. Climatologia de precipitação no Amapá e mecanismos climáticos de grande escala. In: A. C. Cunha, E. B. de Souza, e H. F. A. Cunha, Tempo, clima e recursos hídricos: Resultados do projeto REMETAP no Estado do Amapá, Macapá-AP: IEPA, 2010. p. 177-195.

SOUZA, L. R.; CUNHA, A. C; BARRETO, N. J. C. BRITO, D. C. Aplicação do Sistema Hidrológico IPHS1 no Estudo de Chuva-Vazão em Aproveitamentos Hidrelétricos na Bacia Hidrográfica do Alto e Médio Araguari: Resultados do Projeto REMETAP no Estado do Amapá. Capítulo 10. (Orgs) CUNHA, A. C.; SOUZA, E. B. e CUNHA, H. F. A. Macapá - AP. IEPA. p 97-118. 2010.

SOUZA, E. B. de. et al. Precipitação sazonal sobre a Amazônia oriental no período chuvoso: Observações e simulações regionais com o RegCM3. Revista Brasileira de Meteorologia, v. 24, n. 2, p.111-124, 2009.
SOUZA, E. B.; ROCHA, E. J. P. Diurnal variation of rainfall in Bragança-PA (eastern Amazon) during rainy season: mean characteristic and extremes events. Revista Brasileira de Meteorologia, v. 21, n. 3a, 2006. p.142-152.

STUKEL, M. R. et al. Top-down, bottom-up and physical controls on diatom-diazotroph assemblage growth in the Amazon River Plume. Biogeosciences Discuss, 10, 2013. p. 13931-13976.

TELEDYNE RD INSTRUMENTS, WorkHorse Rio Grande ADCP. 1999.User's GuideP/N 957-6167-00, November. 2007

TRIPOLI, G.; W. COTTON. The Colorado State University three-dimensional cloud-mesoscale model. Part I: General theorical framework and sensitivity experiments. Journal de Recherches Atmospheriques, v. 16, p. 185-219, 1982.

TUCCI, C. E. M. Modelos hidrológicos. Associação Brasileira de Recursos Hídricos (Editora Universitária). Rio Grande do Sul. 1998. 669p.

WARD, N. D; KEIL, R. G.; MEDEIROS, P. M.; BRITO, D. C.; CUNHA, A.C.; DITTMAR, T.; YAGER, P. L; KRUSCHE, . A. V. e RICHEY, J. E. A Degradation of terrestrially derived macromolecules in the Amazon River. Nature Geoscience, v. 6, p. 530-533, 2013, doi:10.1038/ngeo1817. 